\title{
Exercise training for asbestos-related and other dust-related respiratory diseases: a randomised controlled trial
}

Marita T Dale ${ }^{1,2^{*}}$, Zoe J McKeough ${ }^{1}$, Phillip A Munoz ${ }^{3}$, Peter Corte ${ }^{3}$, Peter T P Bye ${ }^{3,4}$ and Jennifer A Alison ${ }^{1,5}$

\begin{abstract}
Background: The study aimed to determine the short and long-term effects of exercise training on exercise capacity and health-related quality of life (HRQoL) compared to usual care in people with dust-related pleural and interstitial respiratory diseases. No previous studies have specifically evaluated exercise training in this patient population.

Methods: Participants with a diagnosis of a dust-related respiratory disease including asbestosis and asbestos related pleural disease were recruited and randomised to an eight-week exercise training group (EG) or a control group (CG) of usual care. Six-minute walk distance (6MWD), St George's Respiratory Questionnaire (SGRQ) and Chronic Respiratory Disease Questionnaire $(\mathrm{CRQ})$ were measured at baseline, eight weeks and 26 weeks by an assessor blinded to group allocation.

Results: Thirty-three of 35 male participants completed the study. Sixty-nine percent of participants had asbestos related pleural disease. At eight weeks, compared to the CG, the EG showed a significantly increased 6MWD (mean difference $(95 \% \mathrm{Cl})$ ) 53 metres (32 to 74$)$, improved SGRQ total score, -7 points (-13 to -1$)$ and increased CRQ total score, 6.4 points (2.1 to 10.7). At 26 weeks significant between-group differences were maintained in 6MWD, 45 metres (17 to 73) and CRQ total score, 13.1 points (5.2 to 20.9).
\end{abstract}

Conclusion: Exercise training improved short and long-term exercise capacity and HRQoL in people with dust-related pleural and interstitial respiratory diseases.

Clinical trial registration number: ANZCTR12608000147381. Date trial registered: 27.03.2008.

Keywords: Asbestosis, Diffuse pleural thickening, Interstitial lung disease, Exercise, Pulmonary rehabilitation, Physical activity, Health-related quality of life

\section{Background}

Dust-related pleural and interstitial respiratory diseases are a global health problem. Past and ongoing exposure to harmful dusts continue to impact millions of people worldwide [1-3] with the prevalence of some dust-related respiratory diseases increasing [4]. The pathological changes of these diseases include parenchymal and/or pleural fibrosis which may result in shortness of breath at rest or on exertion, reduced exercise capacity and health-related quality of life (HRQoL) [5-8]. Limited treatment options are available

\footnotetext{
* Correspondence: maritad@uni.sydney.edu.au

${ }^{1}$ Clinical and Rehabilitation Sciences, Faculty of Health Sciences, The University of Sydney, Sydney, NSW, Australia

${ }^{2}$ Physiotherapy Department, St Vincent's Hospital, Sydney, NSW, Australia

Full list of author information is available at the end of the article
}

for people with dust-related pleural and interstitial respiratory diseases $[3,9]$.

Interstitial lung disease (ILD) describes a broad range of diseases with diverse aetiologies including idiopathic pulmonary fibrosis (IPF). Recently, exercise training has been shown to improve exercise capacity and HRQoL in people with ILD, predominantly IPF $[10,11]$. While there is an indication from uncontrolled or mixed-disease studies that exercise training may benefit people with dustrelated interstitial respiratory diseases $[12,13]$, no studies using rigorous randomised controlled trial methodology have investigated the effect of exercise training on exercise capacity and HRQoL in people with dust-related pleural and interstitial respiratory diseases. 
Physical activity levels play an important role in health outcomes in people with chronic respiratory diseases. Higher levels of physical activity are associated with health benefits for people with chronic obstructive pulmonary disease (COPD), including greater exercise capacity and a higher single breath diffusing capacity for carbon monoxide $\left(D_{L} C O\right)[14]$. Conversely, lower levels of physical activity are associated with increased morbidity and mortality [15]. The effect of exercise training on physical activity levels in people with dust-related pleural and interstitial respiratory diseases is unknown.

The primary aims of this study were to determine the short and long-term effects of exercise training compared to usual care on exercise capacity and HRQoL in people with dust-related pleural and interstitial respiratory diseases. The secondary aims were to determine whether exercise training improved symptoms and habitual daily physical activity compared to usual care in people with dust-related pleural and interstitial respiratory diseases.

\section{Methods}

\section{Study design}

The study was a multi-centred, assessor blinded, parallel group, randomised controlled trial and was conducted in New South Wales, Australia between January 2009 and July 2011. After enrolment into the study and collection of baseline measures, participants were randomly allocated to either an exercise group (EG) or control group (CG) by a person independent of the recruitment process through a computer-generated randomisation programme. Random allocation with minimisation for disease type (asbestos related pleural disease or other), severity (FVC $<80 \%$ or $\geq 80 \%$ ) and training centre was used.

The study was approved by the Human Research Ethics Committee of Sydney South West Area Health Service and all participants gave written informed consent. The trial was registered with the Australian and New Zealand Clinical Trials Registry (ANZCTR12608000147381).

\section{Participants}

Participants were recruited through the Workers' Compensation Dust Diseases Board (DDB) of New South Wales, Australia, respiratory physicians, support groups, workers' unions and newsletters for returned servicemen. Both males and females were eligible to participate if they had a medical diagnosis of a non-malignant dust-related pleural or interstitial respiratory disease including asbestosis, silicosis and asbestos related pleural disease (defined as diffuse pleural thickening and/or rounded atelectasis). Diagnosis had been established by the participant's respiratory physician or by the DDB Medical Authority which is a panel of respiratory physicians with specialist knowledge in occupational lung disease. The diagnostic process included an occupational history, clinical examination by a physician, radiological findings on chest X-ray and computed tomography scans confirming dust-related pleural and/or interstitial disease, and lung function (spirometry and lung volumes via plethysmography) as previously described [16].

People were excluded from the study if they had mesothelioma; discrete parietal pleural plaques as their only manifestation of dust exposure; cardiovascular, neurological or orthopaedic conditions limiting exercise performance; were on long term oxygen therapy; could not understand English; or had participated in a pulmonary rehabilitation programme within the last 12 months.

\section{Intervention}

The EG participated in individually prescribed exercise training at one of seven pulmonary rehabilitation programmes. All participants completed supervised aerobic exercise training, including both walk and cycle training, three times weekly for eight weeks. The training mode, intensity and duration were based on the recommended guidelines for COPD [17]. For walking training the exercise intensity was $80 \%$ of the average walking speed of the better baseline six-minute walk test (6MWT) and for cycle training the initial intensity was $60 \%$ of peak work rate achieved on the incremental cycle test (ICT). Intensity was progressed weekly by increments of $5 \%$ of the average walking speed or the peak work achieved on the ICT, or if dyspnoea or rate of perceived exertion (RPE) scores (whichever was highest) was less than three on the modified Borg 0-10 scale [18] during an exercise training session. Participants completed a minimum of 15 minutes walking and 15 minutes cycling at each session in the first training week, progressing to 30 minutes of each modality by the final week. Rest periods were permitted as required. Adherence with training was pre-defined as completion of at least $80 \%$ of training sessions. Exercise training did not include strength training and there was no education component. At the completion of the eight week training the EG was not provided with any further advice or guidance on continuing exercise training. The CG did not receive any exercise intervention and continued with their usual medical management for the duration of the study.

\section{Pulmonary function}

Participants performed spirometry and lung volumes (body plethysmography) at baseline and eight weeks and $\mathrm{D}_{\mathrm{L}} \mathrm{CO}$ at baseline only (SensorMedics, Yorba Linda, Ca, USA). Spirometry was also measured at 26 weeks following the intervention period. All tests were performed according to standard protocols [19] and results expressed as a percentage of the predicted values [19-21]. 


\section{Outcome measures}

All participants attended Royal Prince Alfred Hospital (RPAH), Sydney, Australia, for testing at baseline, immediately following eight weeks of exercise training or usual care and again after a further 26 weeks. All outcomes were measured by the same assessor, blinded to group allocation. The primary outcomes for the study were exercise capacity measured by the six-minute walk distance (6MWD) and HRQoL measured by the Chronic Respiratory Disease Questionnaire (CRQ) total score and the St George's Respiratory Questionnaire (SGRQ) total score. Secondary outcomes were peak work rate achieved on the ICT, endurance cycle time, CRQ dyspnoea, fatigue, emotional function and mastery domain scores, SGRQ symptoms, activity and impact domain scores and physical activity measured by an activity monitor. Whilst all primary and secondary outcomes were determined at baseline and eight weeks following the interventions, only 6MWD, HRQoL and physical activity outcomes were measured after a further 26 weeks.

\section{Exercise capacity}

Participants performed two six-minute walk tests (6MWT 1 and 6MWT 2) according to guidelines [22] on a continuous 32-metre oval track at baseline, immediately following the exercise training or eight weeks of usual care period and again after a further 26 weeks. Tests were separated by a minimum of 30 minutes or until heart rate and oxygen saturation had returned to resting values.

On a separate day, participants performed a symptomlimited ICT and endurance cycle test (ECT) on an electromagnetically-braked cycle ergometer (Lode BV, Groningen, The Netherlands). Tests were separated by a minimum of one hour or until heart rate and oxygen saturation had returned to resting values. For the ICT, work rate was increased every minute by a predetermined amount, ranging from 5 to 20 Watts. $\mathrm{min}^{-1}$ according to the participant's self-reported exercise capacity and clinical judgement so that test duration was approximately 10 minutes [23]. For the ECT, work rate was increased to $40 \%$ peak work rate in the first minute and to $80 \%$ peak work rate from the second minute to symptom-limited test termination [24]. During the ICT and ECT participants wore a face mask and breath-by-breath measures for oxygen uptake $\left(\mathrm{VO}_{2}\right)$ and carbon dioxide output $\left(\mathrm{VCO}_{2}\right)$ were obtained (Vmax Encore, SensorMedics, Yorba Linda, USA). Heart rate and $\mathrm{SpO}_{2}$ were simultaneously measured using a pulse oximeter Radical $^{\mathrm{TM}}$, Masimo Corporation, Irvine, USA). Dyspnoea and RPE scores were recorded each minute and at peak work rate using the modified Borg 0-10 scale [18]. Peak work rate from the ICT was compared to predicted normal values [25]. The ICT and ECT were only performed at baseline and eight weeks.

\section{Health-related quality of life (HRQoL)}

Participants completed the Chronic Respiratory Disease Questionnaire (CRQ) and the St George's Respiratory Questionnaire (SGRQ) in random order at baseline, eight and 26 weeks. Both questionnaires have previously been used to evaluate HRQoL in ILD [7]. The minimal important difference (MID) for improvements in HRQoL in people with dust-related pleural and interstitial respiratory diseases has not been established. However, in people with COPD, a change of 0.5 in the mean score per item for the CRQ (calculated by dividing the overall score by the number of questions) has been established as the (MID) [26]. If the actual scores, rather than mean score, are used, the MIDs for each domain are 2.5 for dyspnoea, 2 for fatigue, 3.5 for emotional function, 2 for mastery, and 10 for the CRQ total score. For the SGRQ, the MID is a reduction of four points in the SGRQ total score for people with COPD.

\section{Physical activity}

Physical activity was measured using an activity monitor (SenseWear Pro3 Armband, BodyMedia, Pittsburgh, PA, USA) worn for seven consecutive days when not attending for exercise testing at baseline, eight and 26 weeks. Participants were instructed to wear the activity monitor continuously, removing it only when showering or swimming. Steps per day, metabolic equivalents (METs) and energy expenditure were recorded using the SenseWear Professional software Version 6.1. Compliance was set at a minimum wear time of $>85 \%$ per day for at least three days [27]. If this level of compliance was not achieved, the data were excluded from analysis.

\section{Statistical analysis}

Data were analysed according to the intention-to-treat principle. Statistical analysis was performed on PASWWindows (release 18.0; PASW, Chicago, IL, USA). All baseline data are expressed as mean (standard deviation (SD)). We used an analysis of covariance (ANCOVA) for the primary and secondary endpoints. The ANCOVA model included the outcome measure at baseline as the covariate and the repeat outcome measure (at eight or 26 weeks) and treatment allocation as the fixed factors. The data are presented as mean (95\% confidence interval). The level of significance was set at a $p$-value of $<0.05$.

\section{Sample size}

Due to the paucity of data on exercise training in dustrelated ILD and no data on exercise training in people with pleural disease, the sample size was based on outcomes of exercise training in people with ILD (without IPF) [10]. Twenty-six participants were required to give the study a statistical power of $80 \%$ to detect a difference between groups in 6MWD following exercise training of 
$44 \pm 34 \mathrm{~m}$ with a $5 \%$ significance level and allowing for $25 \%$ loss to follow-up.

\section{Results}

\section{Participants}

Forty-four male participants were assessed with 35 included in the study. Of these 35 participants, 24 (69\%) had asbestos related pleural disease (ARPD), five (14\%) had asbestosis, three (9\%) had silicosis, two (6\%) had combined ARPD and asbestosis, and one (3\%) had mixeddust pneumoconiosis. Thus the majority of participants had pleural not parenchymal lung disease. Only two participants had any evidence of COPD on high resolution computed tomography (HRCT) scan. The reasons for noninclusion of nine participants were pain affecting exercise performance (two), neurological impairment (two), unstable cardiovascular responses during exercise testing (two), parietal pleural plaques only (one), peripheral vascular disease affecting exercise performance (one) and an inability to understand English (one). Baseline characteristics of the 35 participants and the diagnoses of study participants are shown in Table 1 . There were no differences between the groups at baseline.

At eight weeks, 34 participants completed the 6MWT and the HRQoL questionnaires, 33 completed the ICT and the ECT and 31 completed the physical activity measurements. At 26 weeks, 31 participants completed the 6MWT, 33 completed the HRQoL questionnaires and 30 completed the physical activity measurements. The flow of participants is presented in Figure 1. There was no significant change in FVC during the study $(\mathrm{p}=0.823)$. No adverse events were reported during the exercise training.

Participants in the EG attended a mean (SD) of 20 (5) exercise training sessions. Fifteen participants were adherent with the exercise training sessions and three participants were non-adherent, attending three, nine and 17 training sessions respectively. The effects of exercise training on 6MWD at eight weeks are shown in Table 2 and Figure 2 and at 26 weeks are shown in Table 3 and Figure 2. The 6MWD was significantly greater in the EG compared to the CG at eight weeks, mean difference $53 \mathrm{~m}$ (95\% CI 32 to 74 ). At 26 weeks the mean (SD) 6MWD for the EG was 525 (81) metres and for the CG was 466 (101) metres. There was a between group difference in the change in 6MWD from baseline to 26 weeks of $45 \mathrm{~m}(95 \% \mathrm{CI} 17$ to 73$)(\mathrm{p}=0.003)$ which was significant in favour of the EG (Figure 2).

At eight weeks, peak work rate and endurance cycle time were significantly greater in the EG than the CG (Table 2). In addition, at eight weeks, heart rate at isowork rate on the ICT was significantly lower in the EG than the CG and Borg dyspnoea score at isotime on the ECT was significantly lower in the EG than the CG (Table 2).
Table 1 Baseline characteristics, disease type, exercise capacity and health-related quality of life of the study participants

\begin{tabular}{|c|c|c|}
\hline & $\begin{array}{l}\text { Exercise training group } \\
\mathrm{n}=18 \\
\text { Mean (SD) }\end{array}$ & $\begin{array}{l}\text { Control group } \\
\mathrm{n}=17 \\
\text { Mean (SD) }\end{array}$ \\
\hline Age, yr & $70(7)$ & $72(6)$ \\
\hline Height, cm & $170(5)$ & $175(6)$ \\
\hline Weight, kg & $80(13)$ & $85(11)$ \\
\hline $\mathrm{BMl}, \mathrm{kg} / \mathrm{m}^{2}$ & $27(4)$ & $28(3)$ \\
\hline ARPD & 11 & 13 \\
\hline Asbestosis & 3 & 2 \\
\hline Asbestosis + ARPD & 1 & 1 \\
\hline Silicosis & 2 & 1 \\
\hline $\begin{array}{l}\text { Mixed-dust } \\
\text { pneumoconiosis }\end{array}$ & 1 & 0 \\
\hline FVC, L & $3.4(0.9)$ & $3.5(0.8)$ \\
\hline FVC, \% pred & $86(23)$ & $86(18)$ \\
\hline $\mathrm{FEV}_{1}, \mathrm{~L}$ & $2.1(0.6)$ & $2.4(0.6)$ \\
\hline $\mathrm{FEV}_{1}, \%$ pred & $75(23)$ & $81(16)$ \\
\hline $\mathrm{FEV}_{1} / \mathrm{FVC}, \%$ & $64(11)$ & $69(7)$ \\
\hline $\mathrm{FEV}_{1} / \mathrm{FVC}, \%$ pred & $88(16)$ & $95(10)$ \\
\hline TLC, \% pred & $83(20)$ & $79(15)$ \\
\hline FRC, \% pred & $82(28)$ & $77(15)$ \\
\hline $\mathrm{RV}, \%$ pred & $77(34)$ & $72(19)$ \\
\hline $\mathrm{D}_{\mathrm{L}} \mathrm{CO}, \%$ pred & $54(15)$ & $57(13)$ \\
\hline $\mathrm{KCO}, \%$ pred & $77(22)$ & $82(19)$ \\
\hline Smoking history, pack year & $18(18)$ & $16(25)$ \\
\hline 6MWD, m & $474(77)$ & $469(81)$ \\
\hline SGRQ Total & $30(15)$ & $29(19)$ \\
\hline SGRQ Activity & $42(21)$ & $42(28)$ \\
\hline SGRQ Symptoms & $38(19)$ & $32(20)$ \\
\hline SGRQ Impacts & $20(14)$ & $20(17)$ \\
\hline CRQ Total & $105(13)$ & $100(13)$ \\
\hline CRQ Dyspnoea & $17(7)$ & $20(6)$ \\
\hline CRQ Fatigue & $20(5)$ & $21(3)$ \\
\hline CRQ Emotional Function & $40(7)$ & $40(6)$ \\
\hline CRQ Mastery & $23(4)$ & $23(4)$ \\
\hline Average daily steps & $7897(2557)$ & $8347(3981)$ \\
\hline Average daily EE, cal & $2373(349)$ & $2660(521)$ \\
\hline Average daily METs & $1.3(0.1)$ & $1.3(0.2)$ \\
\hline
\end{tabular}

$\mathrm{n}=$ number; $\mathrm{SD}=$ standard deviation; $\mathrm{yr}=$ year; $\mathrm{cm}=$ centimetre; $\mathrm{kg}=$ kilogram $\mathrm{BMI}=$ body mass index; $\mathrm{m}=$ metre; $\mathrm{ARPD}=$ asbestos related pleural disease; $\mathrm{FVC}=$ forced vital capacity; $\mathrm{L}=$ litre; $\%$ pred = percentage of predicted value; $\mathrm{FEV}_{1}=$ forced expiratory volume in one second; $\mathrm{TLC}=$ total lung capacity; $\mathrm{FRC}$ = functional residual capacity; $\mathrm{RV}=$ residual volume; $\mathrm{D}_{\mathrm{L}} \mathrm{CO}=$ diffusing capacity for carbon monoxide; $\mathrm{KCO}=$ carbon monoxide transfer coefficient; $6 \mathrm{MWD}=$ six-minute walk distance; $\mathrm{SGRQ}=$ St George's Respiratory Questionnaire $\mathrm{CRQ}=$ Chronic Respiratory Disease Questionnaire; $\mathrm{EE}=$ energy expenditure; $\mathrm{cal}=$ calorie; $\mathrm{MET}=$ metabolic equivalent 


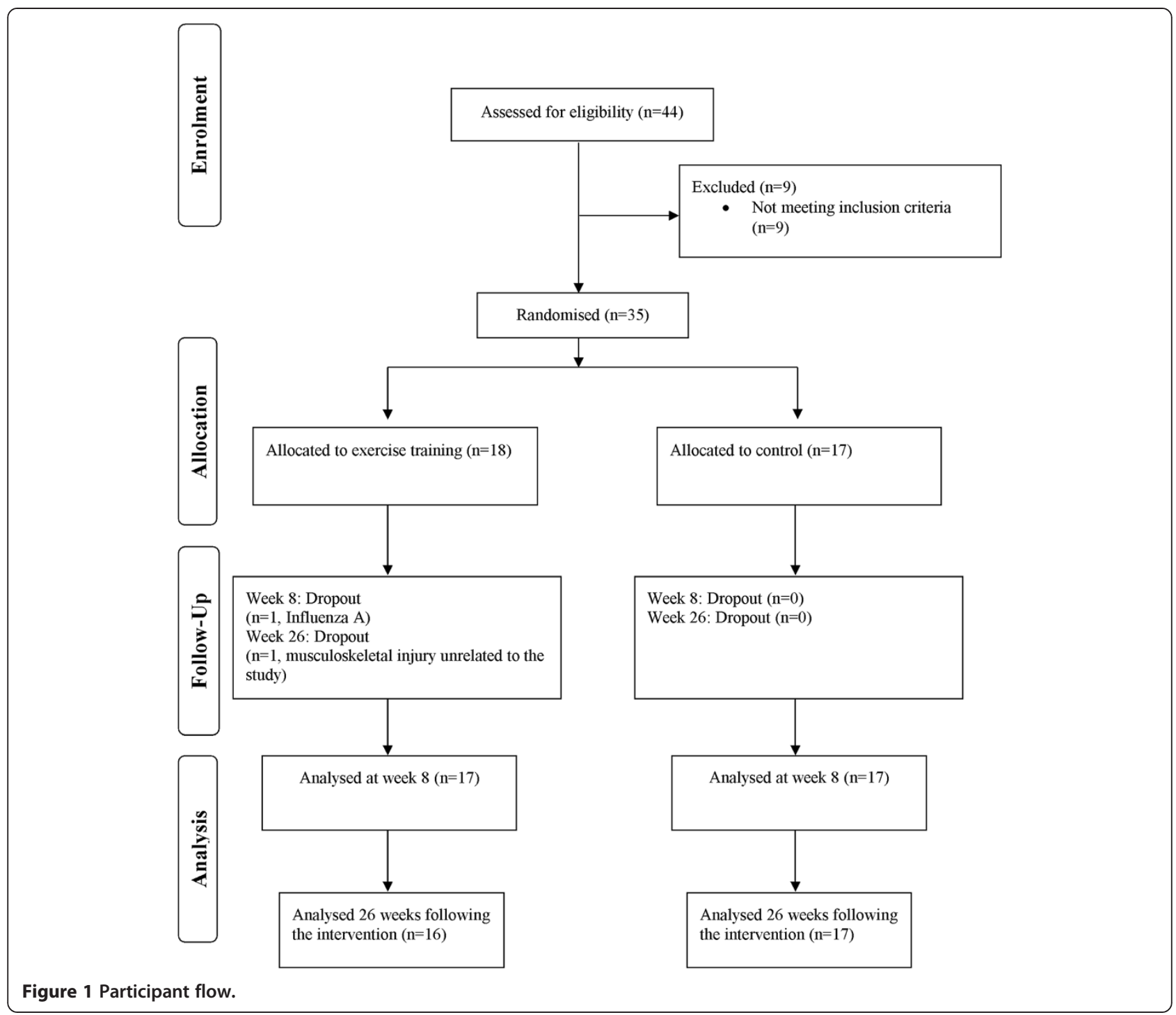

HRQoL significantly improved in the EG compared to the CG at eight weeks (Table 3). The CRQ total score and domain scores for dyspnoea, emotional function and mastery and the SGRQ total and symptoms scores demonstrated significantly improved scores in the EG compared to the CG at eight weeks. At 26 weeks, the difference between groups in the CRQ total score and CRQ domains were maintained. However, there were no differences between groups in the SGRQ domains at 26 weeks (Table 3).

There were small statistically significant improvements in measures of physical activity (average daily steps and average daily METs) at eight weeks in the EG compared to the CG (Table 3). Although the improvement in average daily METs was maintained at 26 weeks in the EG, the difference between groups was very small, 0.11 METs (95\% CI 0.03 to 2.0). At 26 weeks there was no significant difference in average daily steps between the EG and the CG.

\section{Discussion}

This is the first randomised controlled trial to examine the effects of exercise training on exercise capacity and HRQoL in people with dust-related pleural and interstitial respiratory diseases. This study demonstrated improvements in exercise capacity and HRQoL immediately following an exercise training programme compared to a control group of usual care, with improvements in the exercise training group sustained at 26 weeks following intervention.

Exercise training improved functional exercise capacity measured by an increase of 53 metres in 6MWD in this cohort of people with dust-related pleural and interstitial respiratory diseases. This magnitude of change was larger than the 20 to 35 metre improvements reported in people with ILD $[10,11]$ and similar to the 48 metre improvement after exercise training in people with COPD [28]. In our study, the improvement in 6MWD was maintained 
Table 2 Mean (SD) of groups, mean (SD) difference within groups, mean $(95 \% \mathrm{CI})$ difference between groups for exercise capacity immediately following intervention

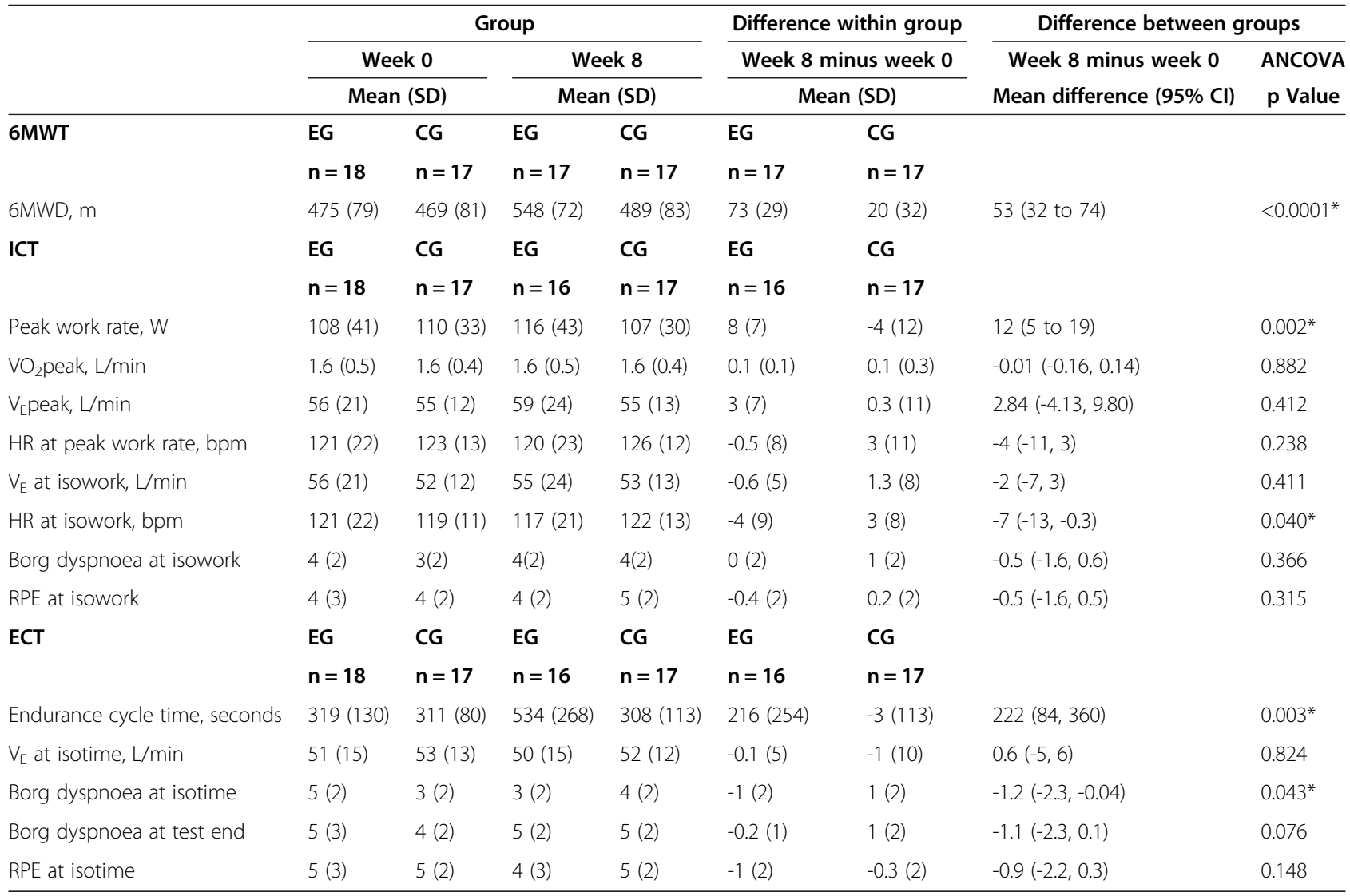

$\mathrm{SD}=$ standard deviation; $\mathrm{Cl}=$ confidence interval; $\mathrm{ANCOVA}=$ analysis of covariance; $6 \mathrm{MWT}=$ six minute walk test; $\mathrm{EG}=$ exercise training group; $\mathrm{CG}=$ control group; $\mathrm{n}=$ number; $6 \mathrm{MWD}=$ six minute walk distance; $\mathrm{m}=$ metre; $\mathrm{ICT}=$ incremental cycle test; $\mathrm{W}=$ watts; $\mathrm{VO}_{2}$ peak = peak oxygen uptake; $\mathrm{L} /$ min = litres per minute; $\mathrm{V}_{\mathrm{E}}$ peak = minute ventilation at peak work rate; $\mathrm{HR}=$ heart rate; $\mathrm{bpm}=$ beats per minute; $\mathrm{V}_{\mathrm{E}}=$ minute ventilation; $\mathrm{RPE}=$ rate of perceived exertion; $\mathrm{ECT}=\mathrm{endurance}$ cycle test; *p $<0.05$.

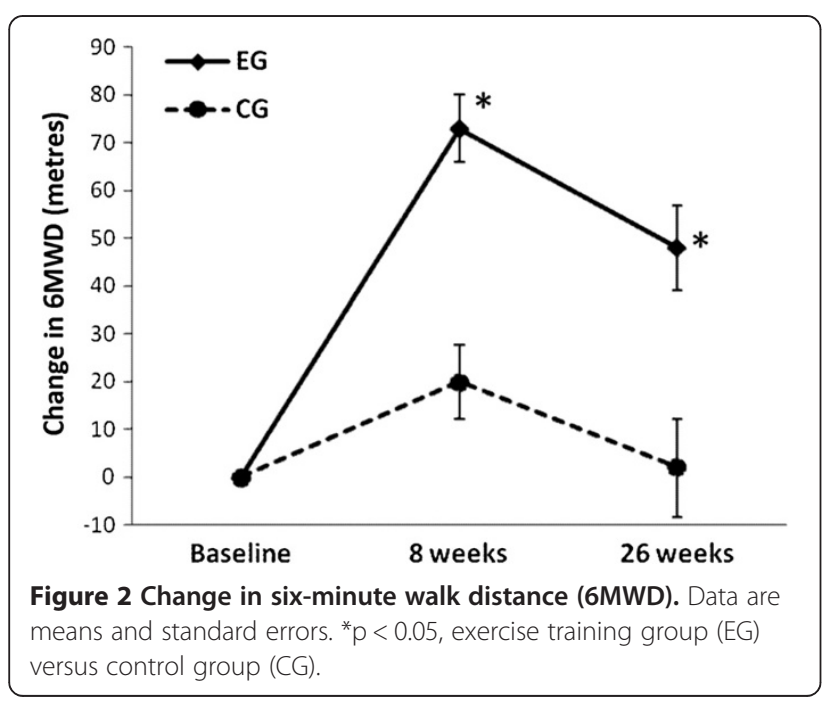

26 weeks after the completion of supervised exercise training without ongoing supervised exercise. This finding differs from the study by Holland et al where improvements in 6MWD were not maintained at 26 weeks in people with ILD, predominantly IPF [10]. One possible explanation is that our cohort included participants with mild to moderate dust-related pleural and interstitial respiratory diseases rather than more severe ILD. Our participants also had relatively stable disease over the study period, as evident by the stability of the FVC over 26 weeks, compared to the significant decline in FVC over a similar period in the study by Holland et al, indicating the progressive and severe nature of ILD in their cohort.

Exercise training also resulted in improvements in peak and endurance exercise capacity. Compared to the CG, the EG achieved a mean improvement of 12 watts in peak exercise capacity and a significant reduction in heart rate of 7 beats/minute at isowork rate. In the absence of changes to ventilatory parameters, these findings indicate that cardiovascular and peripheral muscle adaptations consistent with known training effects occurred. Participants in the EG 
Table 3 Differences between the exercise training and control groups immediately following intervention and 26 weeks following intervention for exercise capacity, health-related quality of life and physical activity

\begin{tabular}{|c|c|c|c|c|}
\hline Outcome & $\begin{array}{c}\text { Week } 8 \text { minus week } 0 \\
\text { Mean difference } \\
(95 \% \mathrm{Cl})\end{array}$ & $\begin{array}{l}\text { ANCOVA } \\
\text { p Value }\end{array}$ & $\begin{array}{c}\text { Week } 26 \text { minus week } 0 \\
\text { Mean difference } \\
(95 \% \mathrm{Cl})\end{array}$ & $\begin{array}{l}\text { ANCOVA } \\
\text { p Value }\end{array}$ \\
\hline Exercise capacity & $\mathrm{n}=34$ & & $\mathrm{n}=31$ & \\
\hline $6 \mathrm{MWD}, \mathrm{m}$ & $53(32,74)$ & $<0.001^{*}$ & $45(17,73)$ & $0.003^{*}$ \\
\hline HRQoL & $\mathrm{n}=34$ & & $\mathrm{n}=33$ & \\
\hline SGRQ Total & $-7(-13,-1)$ & $0.033^{*}$ & $-4(-12,4)$ & 0.293 \\
\hline SGRQ Symptoms & $-15(-27,-2)$ & $0.021^{*}$ & $-4(-18,9)$ & 0.530 \\
\hline SGRQ Activity & $-5(-13,3)$ & 0.209 & $-4(-15,8)$ & 0.505 \\
\hline SGRQ Impacts & $-5(-12,2)$ & 0.183 & $-4(-12,5)$ & 0.383 \\
\hline CRQ Total & $6.4(2.1,10.7)$ & $0.005^{*}$ & 13.1 (5.2 to 20.9$)$ & $0.002^{*}$ \\
\hline CRQ Dyspnoea & $2.2(0.6,3.7)$ & $0.007^{*}$ & $3.4(1.5,5.4)$ & $0.001^{*}$ \\
\hline CRQ Fatigue & $1.3(-0.02,2.6)$ & 0.053 & $2.9(0.6,5.2)$ & $0.015^{*}$ \\
\hline CRQ Emotional Function & $2.4(0.7,4.2)$ & $0.008^{*}$ & $5.5(2.0,8.9)$ & $0.003^{*}$ \\
\hline CRQ Mastery & $1.4(0.1,2.7)$ & $0.036^{*}$ & $2.7(1.0,4.3)$ & $0.002^{*}$ \\
\hline Physical activity & $\mathrm{n}=31$ & & $\mathrm{n}=30$ & \\
\hline Average daily steps & $1514(15,3012)$ & $0.048^{*}$ & $1206(-156,2568)$ & 0.08 \\
\hline Average daily EE, cal & $86(-57,230)$ & 0.227 & $158(-8,323)$ & 0.062 \\
\hline Average daily METs & $0.08(0.01,0.15)$ & $0.038^{*}$ & $0.11(0.03,0.20)$ & $0.012^{*}$ \\
\hline
\end{tabular}

$\mathrm{Cl}=$ confidence interval; $\mathrm{ANCOVA}=$ analysis of covariance; $\mathrm{n}=$ number; $6 \mathrm{MWD}=$ six-minute walk distance; $\mathrm{m}=\mathrm{metre}$; $\mathrm{HRQ} \mathrm{L}=\mathrm{health}$-related quality of life; $\mathrm{SGRQ}=$ St George's Respiratory Questionnaire; $\mathrm{CRQ}=$ Chronic Respiratory Disease Questionnaire; $\mathrm{EE}=$ energy expenditure; cal $=$ calorie; $\mathrm{MET}=$ metabolic equivalent. *p $<0.05$.

also improved their endurance exercise capacity with a mean improvement of 222 seconds in endurance cycle time following exercise training and a reduction of perceived breathlessness at endurance isotime, which has not been previously reported in people with ILD. Therefore, exercise training in people with dust-related pleural and interstitial respiratory diseases yielded a similar improvement in endurance exercise capacity as those with COPD who demonstrated improvements in endurance cycle time of 198 (352) seconds following an exercise training programme [29].

The minimal important difference for improvements in exercise capacity in people with dust-related pleural and interstitial respiratory diseases has not been determined. However, the improvement in $6 \mathrm{MWD}$ in the EG in our study was considerably greater than the reported MID of 35 metres for the 6MWT in people with COPD [30] and the MID ranging from 29-34 metres in people with diffuse parenchymal lung disease [31]. The improvements in endurance cycle time and peak work rate in people with dust-related pleural and interstitial respiratory diseases were also greater than the MID ranging from 100-200 seconds [29] and 3-5 watts [32] respectively in people with COPD. Therefore, the use of a similar exercise training regimen for people with dust-related pleural and interstitial respiratory diseases, as has been previously used in COPD [17], resulted in improvements in exercise capacity that exceeded the MID established for people with COPD or other ILD.

Important improvements in HRQoL were achieved in people with dust-related pleural and interstitial respiratory diseases immediately following exercise training. The improvement in SGRQ total score was greater than the clinically important reduction of 4 points for people with COPD [33]. Despite statistically significant improvements in the CRQ total score and domains of dyspnoea and emotional function, these improvements did not reach the MID established for COPD. Twenty-six weeks following the intervention the significant difference between groups was maintained and interestingly the values of the EG group increased further and reached the MID in all domains of the CRQ. The improvements in HRQoL occurred with exercise training, in the absence of an education component, as has previously been shown in COPD [34]. This study has also demonstrated that the SGRQ and CRQ, which are disease specific questionnaires originally designed to assess HRQoL in people with COPD, can also be used to detect changes in HRQoL in people with dustrelated pleural and interstitial respiratory diseases.

This is the first study to evaluate the effects of exercise training on levels of daily physical activity in people with dust-related pleural and interstitial respiratory diseases. In epidemiological studies, higher levels of physical activity have been associated with health benefits in people with 
COPD $[14,15]$ but this has not been evaluated in ILD or pleural respiratory diseases. Our study demonstrated small but significant improvements in physical activity after exercise training compared to a control group of usual care, both in the short-term (eight weeks) and the longer term (26 weeks). A recent meta-analysis demonstrated a very small increase in physical activity after exercise training in people with COPD [35]. Although the improvement in average daily METs in our study was maintained following exercise training in the longer term, the small magnitude of improvement questions the clinical relevance of this finding. More research is needed to identify how best to improve activity levels in this patient population and whether improvements in physical activity are associated with improved health outcomes.

The development of dust-related pleural and interstitial respiratory diseases is characterized by a long latency period from exposure to dust to development of disease [3]. Consequently, the mean age of participants was 71 years. With increasing age, the $\mathrm{FEV}_{1} / \mathrm{FVC}$ ratio decreases. While the mean $\mathrm{FEV}_{1} / \mathrm{FVC}$ ratio in our participants was less than $0.7, \mathrm{FEV}_{1} / \mathrm{FVC}$ ratio as a percent of predicted was within the normal range for people of this age [21] and did not reflect the presence of COPD. The HRCT findings further confirmed that only two participants had any evidence of COPD. Thus the findings of this study are specifically related to asbestos-related and other dust-related respiratory disease and are not confounded by co-existing COPD.

The original sample size calculation was based on outcomes of exercise training in people with ILD. As the study progressed, two distinct participant groups became evident, participants with dust-related pleural disease and participants with dust-related interstitial lung disease. To account for this heterogeneity, more participants were recruited than originally calculated.

There are several limitations to this study. Incremental and endurance cycle ergometry tests were not repeated at 26 weeks thus it is unknown whether improvements in peak and endurance exercise capacity shown at eight weeks were maintained in the longer term. In addition, participants did not complete resistance training as part of the exercise training therefore the effects of resistance training in this population remain unclear. While recruitment was open to males and females, only males volunteered to participate in the study, so the findings cannot be extrapolated to females with dust-related respiratory diseases. Since our study population did not include people with dust-related pleural and interstitial respiratory diseases who were on long term oxygen therapy and as our participants did not have severe disease, the findings of our study cannot be extrapolated to such sub-groups. Finally, there was some heterogeneity in the diagnoses of study participants which limit the generalisation of the findings. More studies of each specific disease group are needed to address the paucity of literature on the specific effects of exercise training in people with dust-related pleural disease and dust-related interstitial lung disease. Such diseases usually have a slower progression than other ILDs and thus interventions such as exercise training that improve exercise capacity, quality of life and levels of daily physical activity may have an important role in the management of these diseases that previously have had few effective therapies.

\section{Conclusion}

This randomised controlled trial demonstrated that exercise training improved short and long-term exercise capacity and health-related quality of life in people with dust-related pleural and interstitial respiratory diseases. Commonly, people with dust-related pleural and interstitial respiratory diseases have not been considered appropriate for referral to pulmonary rehabilitation programmes due to the lack of evidence of benefit. This study has provided compelling evidence for the benefits of exercise training in people with dust-related pleural and interstitial respiratory diseases and for the inclusion of this population in pulmonary rehabilitation programmes.

\section{Abbreviations}

HRQoL: Health-related quality of life; ILD: Interstitial lung disease;

IPF: Idiopathic pulmonary fibrosis; COPD: Chronic obstructive pulmonary disease; $D_{L} C O$ : Diffusing capacity for carbon monoxide; EG: Exercise training group; CG: Control group; FVC: Forced vital capacity; DDB: Dust Diseases Board; 6MWT: Six-minute walk test; ICT: Incremental cycle test; RPE: Rate of perceived exertion; RPAH: Royal Prince Alfred Hospital; 6MWD: Six-minute walk distance; CRQ: Chronic Respiratory Disease Questionnaire; SGRQ: St George's Respiratory Questionnaire; ECT: Endurance cycle test; $\mathrm{VO}_{2}$ : Oxygen uptake; $\mathrm{VCO}_{2}$ : Carbon dioxide output; $\mathrm{SpO}_{2}$ : Oxygen saturation; MID: Minimal important difference; MET: Metabolic equivalent; SD: Standard deviation; ANCOVA: Analysis of covariance; ARPD: Asbestos related pleural disease; HRCT: High resolution computed tomography; Cl: Confidence interval; $\mathrm{FEV}_{1}$ : Forced expiratory volume in one second.

\section{Competing interests}

The authors declare that they have no competing interests.

\section{Authors' contributions}

MD: study design, data collection, data analysis and interpretation, writing of the manuscript, guarantor of overall content. ZM: study design, data collection, data analysis and interpretation, writing of the manuscript. PM: data collection and writing of the manuscript. PC: study design and writing of manuscript. PB: study design and writing of manuscript. JA: study design, data collection, data analysis and interpretation, writing of the manuscript, guarantor of overall content. All authors read and approved the final manuscript.

\section{Acknowledgements}

The authors would like to thank the Research and Education Unit at the Workers' Compensation Dust Diseases Board (DDB) of New South Wales and the Respiratory Investigation Unit at Royal Prince Alfred Hospital for their assistance with recruitment. The authors would also like to thank the Pulmonary Rehabilitation sites at Royal Prince Alfred Hospital, Concord Repatriation General Hospital, The Prince of Wales Hospital, St George Hospital, Gosford Hospital, Wollongong Hospital and John Hunter Hospital for their assistance with exercise training and Honorary Professor Jenny Peat for review and advice on statistical analysis. 


\section{Support}

The study was funded by a competitive grant from the Workers'

Compensation Dust Diseases Board (DDB) of New South Wales, Australia.

\section{Author details}

${ }^{1}$ Clinical and Rehabilitation Sciences, Faculty of Health Sciences, The University of Sydney, Sydney, NSW, Australia. 'Physiotherapy Department, St Vincent's Hospital, Sydney, NSW, Australia. ${ }^{3}$ Department of Respiratory Medicine, Royal Prince Alfred Hospital, Sydney, NSW, Australia. ${ }^{4}$ Sydney Medical School, The University of Sydney, Sydney, NSW, Australia. ${ }^{5}$ Department of Physiotherapy, Royal Prince Alfred Hospital, Sydney, NSW, Australia.

Received: 29 June 2014 Accepted: 17 October 2014

Published: 18 November 2014

\section{References}

1. Kazan-Allen L: Asbestos and mesothelioma: worldwide trends. Lung Cancer 2005, 49(Suppl 1):S3-S8.

2. Le GV, Takahashi K, Park E-K, Delgermaa V, Oak C, Qureshi AM, Aljunid SM: Asbestos use and asbestos-related diseases in Asia: past, present and future. Respirology 2011, 16(5):767-775.

3. American Thoracic Society: Diagnosis and initial management of nonmalignant diseases related to asbestos. Am J Respir Crit Care Med 2004, 170(6):691-715.

4. Cugell DW, Kamp DW: Asbestos and the pleura: a review. Chest 2004, 125(3):1103-1117.

5. Lee YC, Singh B, Pang SC, de Klerk NH, Hillman DR, Musk AW: Radiographic (ILO) readings predict arterial oxygen desaturation during exercise in subjects with asbestosis. Occup Environ Med 2003, 60(3):201-206.

6. Picado C, Laporta D, Grassino A, Cosio M, Thibodeau M, Becklake MR: Mechanisms affecting exercise performance in subjects with asbestosrelated pleural fibrosis. Lung 1987, 165(1):45-57.

7. Chang JA, Curtis JR, Patrick DL, Raghu G: Assessment of health-related quality of life in patients with interstitial lung disease. Chest 1999, 116(5):1175-1182.

8. Dale MT, McKeough ZJ, Munoz PA, Corte P, Bye PTP, Alison JA: Functional exercise capacity and health related quality of life in people with asbestos related pleural disease: an observational study. BMC Pulm Med 2013, 13:1.

9. Wagner GR: Asbestosis and silicosis. Lancet 1997, 349(9061):1311-1315.

10. Holland AE, Hill CJ, Conron M, Munro P, McDonald CF: Short term improvement in exercise capacity and symptoms following exercise training in interstitial lung disease. Thorax 2008, 63(6):549-554.

11. Nishiyama O, Kondoh Y, Kimura T, Kato K, Kataoka K, Ogawa T, Watanabe F, Arizono S, Nishimura K, Taniguchi H: Effects of pulmonary rehabilitation in patients with idiopathic pulmonary fibrosis. Respirology 2008, 13(3):394-399.

12. Cockcroft AE, Saunders MJ, Berry G: Randomised controlled trial of rehabilitation in chronic respiratory disability. Thorax 1981, 36(3):200-203.

13. Dalichau S, Demedts A, im Sande A, Moller T: Short- and long-term effects of the outpatient medical rehabilitation for patients with asbestosis. Pneumologie 2010, 64(3):163-170.

14. Garcia-Aymerich J, Serra I, Gomez FP, Farrero E, Balcells E, Rodriguez DA, de Batlle J, Gimeno E, Donaire-Gonzalez D, Orozco-Levi M, Sauleda J, Gea J, Rodriguez-Roisin R, Roca J, Agusti AG, Anto JM: Physical activity and clinical and functional status in COPD. Chest 2009, 136(1):62-70.

15. Garcia-Aymerich J, Lange P, Benet M, Schnohr P, Anto JM: Regular physical activity reduces hospital admission and mortality in chronic obstructive pulmonary disease: a population based cohort study. Thorax 2006, 61(9):772-778.

16. Park EK, Hannaford-Turner KM, Hyland RA, Johnson AR, Yates DH: Asbestosrelated occupational lung diseases in NSW, Australia and potential exposure of the general population. Ind Health 2008, 46(6):535-540.

17. Nici L, Donner C, Wouters E, Zuwallack R, Ambrosino N, Bourbeau J, Carone M, Celli B, Engelen M, Fahy B, Garvey C, Goldstein R, Gosselink R, Lareau S, Maclntyre N, Maltais F, Morgan M, O'Donnell D, Prefault C, Reardon J, Rochester C, Schols A, Singh S, Troosters T: American Thoracic Society/ European Respiratory Society statement on pulmonary rehabilitation. Am J Respir Crit Care Med 2006, 173(12):1390-1413.

18. Borg GA: Psychophysical bases of perceived exertion. Med Sci Sports Exerc 1982, 14(5):377-381.
19. Quanjer PH, Tammeling GJ, Cotes JE, Pedersen OF, Peslin R, Yernault JC: Lung volumes and forced ventilatory flows. Report Working Party Standardization of Lung Function Tests, European Community for Steel and Coal. Official Statement of the European Respiratory Society. Eur Respir J Suppl 1993, 16:5-40.

20. Crapo RO, Morris AH: Standardized single breath normal values for carbon monoxide diffusing capacity. Am Rev Respir Dis 1981, 123(2):185-189.

21. Hankinson JL, Odencrantz JR, Fedan KB: Spirometric reference values from a sample of the general U.S. population. Am J Respir Crit Care Med 1999, 159(1):179-187.

22. ATS Committee on Proficiency Standards for Clinical Pulmonary Function Laboratories: ATS statement: guidelines for the six-minute walk test. Am J Respir Crit Care Med 2002, 166(1):111-117.

23. ERS Task Force on Standardization of Clinical Exercise Testing: Clinical exercise testing with reference to lung diseases: indications, standardization and interpretation strategies. Eur Respir J 1997, 10(11):2662-2689.

24. Oga T, Nishimura K, Tsukino M, Sato S: Exercise responses during endurance testing at different intensities in patients with COPD. Respir Med 2004, 98(6):515-521.

25. Jones NL, Makrides L, Hitchcock C, Chypchar T, McCartney N: Normal standards for an incremental progressive cycle ergometer test. Am Rev Respir Dis 1985, 131(5):700-708.

26. Jaeschke R, Singer J, Guyatt GH: Measurement of health status: Ascertaining the minimal clinically important difference. Control Clin Trials 1989, 10(4):407-415.

27. Watz $H$, Waschki B, Meyer T, Magnussen H: Physical activity in patients with COPD. Eur Respir J 2009, 33(2):262-272.

28. Lacasse Y, Goldstein R, Lasserson TJ, Martin S: Pulmonary rehabilitation for chronic obstructive pulmonary disease. Cochrane Database Syst Rev 2006, 4:CD003793.

29. Laviolette L, Bourbeau J, Bernard S, Lacasse Y, Pepin V, Breton MJ, Baltzan M, Rouleau M, Maltais F: Assessing the impact of pulmonary rehabilitation on functional status in COPD. Thorax 2008, 63(2):115-121.

30. Puhan MA, Mador MJ, Held U, Goldstein R, Guyatt GH, Schunemann HJ: Interpretation of treatment changes in 6-minute walk distance in patients with COPD. Eur Respir J 2008, 32(3):637-643

31. Holland AE, Hill CJ, Conron M, Munro P, McDonald CF: Small changes in six-minute walk distance are important in diffuse parenchymal lung disease. Respir Med 2009, 103(10):1430-1435.

32. Puhan MA, Chandra D, Mosenifar Z, Ries A, Make B, Hansel NN, Wise RA, Sciurba F, National Emphysema Treatment Trial Research Group: The minimal important difference of exercise tests in severe COPD. Eur Respir J 2011, 37(4):784-790.

33. Jones PW: Interpreting thresholds for a clinically significant change in health status in asthma and COPD. Eur Respir J 2002, 19(3):398-404.

34. Blackstock FC, Webster KE, McDonald CF, Hill CJ: Comparable improvements achieved in chronic obstructive pulmonary disease through pulmonary rehabilitation with and without a structured educational intervention: a randomized controlled trial. Respirology 2014, 19:193-202.

35. Ng LW, Mackney J, Jenkins S, Hill K: Does exercise training change physical activity in people with COPD? A systematic review and meta-analysis. Chron Respir Dis 2012, 9(1):17-26.

doi:10.1186/1471-2466-14-180

Cite this article as: Dale et al:: Exercise training for asbestos-related and other dust-related respiratory diseases: a randomised controlled trial. BMC Pulmonary Medicine 2014 14:180. 